\title{
Suicide by occupation: systematic review and meta-analysis
}

\author{
Allison Milner, Matthew J. Spittal, Jane Pirkis and Anthony D. LaMontagne
}

\section{Background}

Previous research has shown that those employed in certain occupations, such as doctors and farmers, have an elevated risk of suicide, yet little research has sought to synthesise these findings across working-age populations.

\section{Aims \\ To summarise published research in this area through systematic review and meta-analysis.}

\section{Method}

Random effects meta-analyses were used to calculate a pooled risk of suicide across occupational skill-level groups.

\section{Results}

Thirty-four studies were included in the meta-analysis. Elementary professions (e.g. labourers and cleaners) were at elevated risk compared with the working-age population (rate ratio $(\mathrm{RR})=1.84,95 \% \mathrm{Cl} 1.46-2.33)$, followed by machine operators and deck crew (RR $=1.78,95 \% \mathrm{Cl} 1.22-2.60)$ and agricultural workers ( $R R=1.64,95 \% \mathrm{Cl} 1.19-2.28$ ). Results suggested a stepwise gradient in risk, with the lowest skilled occupations being at greater risk of suicide than the highest skill-level group.

\section{Conclusions}

This is the first comprehensive meta-analytical review of suicide and occupation. There is a need for future studies to investigate explanations for the observed skill-level differences, particularly in people employed in lower skill-level groups.

\section{Declaration on interest}

None.
Numerous studies have found that certain occupations such as medical professionals (including doctors, nurses, veterinarians), ${ }^{1-5}$ farmers $^{6-8}$ and police ${ }^{9-11}$ are at elevated risk of suicide compared with the general employed population. This could be explained by access to lethal means through work, as in the case of farmers reported to have taken their own life using firearms. ${ }^{12}$ Wider socioeconomic determinants and work-related factors, including exposure to stressful working conditions, could also influence the relationship between occupation and suicide. ${ }^{13-17}$ A problem common to many studies on this topic is that they are based on limited sample sizes, hindering statistical power to detect small effects. This article sought to examine the relationship between occupation and suicide across the full evidence base through systematic review and meta-analysis, thereby building on past narrative reviews. ${ }^{18,19}$ In addition to offsetting statistical power limitations common to single studies, the review sought to investigate higher order patterning by occupational skill level or status. This was made possible through the classification of occupations according to a hierarchical internationally recognised coding framework. The main hypothesis of this study was that risk of suicide would vary by occupational skill level. The rationale for this hypothesis stems from past research demonstrating that psychosocial job stressors pattern by occupational skill level and that psychosocial job stressors are associated with mental illness. ${ }^{20}$

\section{Method}

\section{Search strategy}

The review was conducted according to the PRISMA guidelines (www.prisma-statement.org/). The search strategy targeted studies that reported information on suicide by occupation, published from 1950 until May 2012. Computer-based internet databases used for this search included: PubMed, Web of Science, Proquest and Scopus. The combinations of keywords used in the database search included: occupation* AND suicid ${ }^{\star}$; work ${ }^{\star}$ AND suicid ${ }^{*}$; job AND suicid ${ }^{\star}$. The search was also run using terms such as intentional self harm* ${ }^{*}$. A secondary search examined the reference list of all retained articles. Both published and unpublished reports were considered in the review process. The initial data searches were conducted by A.D.M. Subsequent data checking and searches were overseen by M.J.S., J.P. and A.D.L, and mismatches in classification of studies were resolved by consensus.

\section{Eligibility criteria and selection of studies}

Only studies that had the key search terms in the abstract and suicidal behaviours as an outcome variable were considered. Conceptual articles were excluded. Following this, only articles that provided a clear assessment of occupation and that were in English were included. Qualitative studies were removed, leaving retrospective population-level studies, case-control studies, meta-analyses and systematic reviews. Preference was given to those studies able to provide information across representative populations (for example coverage across entire occupational groups), rather than smaller samples within specific populations. Research on suicide mortality (i.e. no articles on suicide ideation or attempts) was retained. All effect-size estimates were considered, including odds ratios (ORs), rate ratios (RRs), relative risks, proportionate mortality ratios (PMRs) and standardised mortality ratios (SMRs). Estimates needed to present either a standard error or $95 \%$ confidence intervals to be included in the meta-analysis.

\section{Data extraction}

Information extracted from each study included the location of the study, time period the study was conducted, author names, description of occupation, description of the comparison population (or control group), effect size for suicide mortality, confidence intervals and/or standard error.

\section{Coding of occupation}

Occupational grouping was assigned using major codes from the International Standard Classification of Occupations (ISCO) 
(version 2008). ${ }^{21}$ These were: category 1 (managers, senior officials and legislators), category 2 (professionals), category 3 (technicians and associate professionals), category 4 (clerks), category 5 (service and sales workers), category 6 (skilled agricultural and fishery workers), category 7 (craft and related trades workers), category 8 (plant and machine operators, and assemblers), and category 9 (elementary occupations). Military occupations were coded 0 because these are unable to be classified according to skill level. Major groups were coded into four aggregate levels of skill, ${ }^{22}$ from level 1 (the lowest skilled occupations) to level 4 (the highest skilled occupations). Military occupations were excluded from the aggregate skill level. Further information about the coding of occupations included in this review according to major ISCO grouping and aggregate skill level can be found in online Table DS1.

\section{Statistical analysis}

All effect sizes and confidence intervals were log-transformed. Where confidence intervals were unavailable, these were calculated using the standard error of the effect size. To assess the effect of occupational skill level on risk of suicide, separate random-effects meta-analyses were conducted for each occupational subgroup and skill level. The pooled subgroup results were presented on the exponential scale. The pooled effect size represents the risk of suicide among the subgroup of interest compared with the whole working-age population. Heterogeneity between studies was assessed through the $I^{2}$ statistic. Sensitivity analysis was conducted to assess the impact of choosing different referent groups or populations, as well as to examine differences between males and females, and variation based on whether the study controlled for socioeconomic status (SES). Meta-regression was used to assess the extent to which statistical heterogeneity between studies were related to one or more characteristics of the studies. ${ }^{23}$ Funnel plots were used to assess the precision of estimates. ${ }^{24} \mathrm{~A}$ modified Egger's test was used to assess small study effects by performing a linear regression of the effect estimates on their standard errors, weighted by $1 /$ (variance of the intervention effect estimate) ${ }^{25}$ All analyses were conducted using Stata 12.1 for Windows using the 'metan' suite of commands.

\section{Results}

A total of 1290 articles were identified using the search terms (Fig. 1). Initial scan of the title and abstract led to exclusion of duplicates, editorial and conceptual pieces. Review of the abstracts of the remaining 233 studies resulted in the exclusion of 45 case series and qualitative articles, and 29 articles on suicide attempt or ideation and mental illness (leaving only articles on suicide mortality). Following this, 159 full-text articles were read for inclusion. Review of all the reference lists of articles resulted in 21 additional articles being included from the reference lists of all articles retrieved. At the last stage of review, 146 articles were excluded because of incomplete reporting of either effects and/ or occupations, leaving 34 eligible studies.

\section{Quality assessment}

The quality of included studies was guided by past published recommendations. ${ }^{26}$ Those deemed to be of acceptable quality can be found in online Table DS2 (as mentioned above, the grouping of occupations into the ISCO major (skill level) group category and aggregate skill-level groups can be found in Table DS1). Data used in all of the reviewed studies were based on official objective accounts of both occupation and mortality (for example standardised national coding of occupation, coronial determined causes of death). There were four nationally representative retrospective cohort studies included in the metaanalysis. ${ }^{27-30}$ These had reliable coverage (information from the whole country) on both occupational information and mortality from cases and controls across an entire population. However, underreporting was generally not acknowledged or quantified and may bias the results of these studies. Further, the retrospective nature of the studies meant that information was drawn from past exposures. This means that measurement may be incomplete or relatively coarse, particularly when combined with the fact that these studies were developed to examine a number of health outcomes. Twelve studies were based on occupational-specific cohorts that followed people over time. ${ }^{11,31-41}$ The populations from which cases and controls were drawn in these studies are less likely to be representative than those nationally representative studies mentioned above. However, the completeness of recording of mortality outcomes and exposures may be more accurate in these studies because of their focus on health outcomes within specific and defined occupational groups. There were 18 case-control studies (information obtained from retrospective mortality databases) included in the meta-analysis. In these studies, deceased exposed (occupationally coded) individuals were compared with controls. ${ }^{8-10,42-56}$ Some of the studies included in this meta-analysis adjusted for possible confounders such as SES, ${ }^{28,30,46,47,53-55}$ but the majority did not. The highest quality studies were deemed to be those based on nationally representative cohort studies that were able to control for a range of possible confounders and had a control population drawn from the general population. ${ }^{27-30}$

\section{Characteristics of reviewed studies}

Studies included in the review were conducted over a diverse range of time periods and locations. The majority of research on occupational suicide came from high-income areas of the world such as Canada, ${ }^{29,31,47,56}$ the USA ${ }^{8-11,28,40,44,48,50,51,53-55,57}$ and Europe. ${ }^{27,30,32-39,43,45,49}$ There was one study each in Japan, ${ }^{41}$ Korea, ${ }^{46}$ New Zealand ${ }^{52}$ and Australia. ${ }^{42}$ The earliest study was

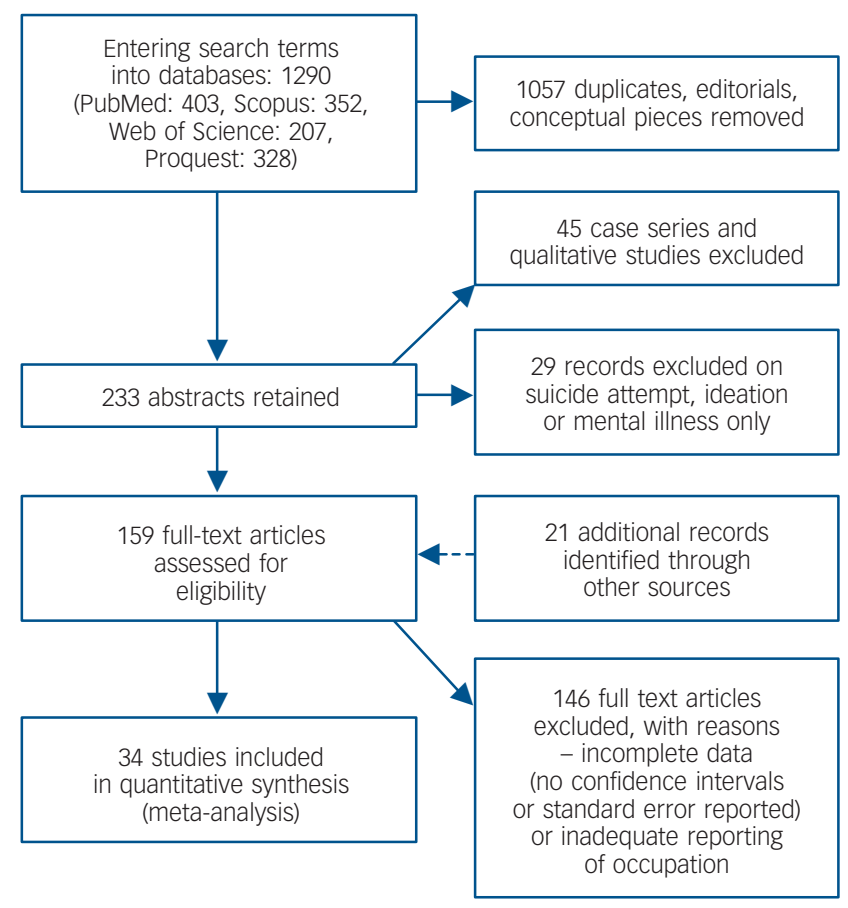

Fig. 1 Selection of studies for meta-analysis. 
conducted in $1979^{37}$ and the latest study included was published in 2012. ${ }^{34}$ Ten studied suicide risk in both males and females, ${ }^{10,29,41,42,46,49-52,55} 13$ studies were based on male suicide $^{8,11,31,32,34-36,38,39,43-45,56}$ and 2 studies analysed female suicide. $^{33,47}$ There were nine studies that examined all person suicides. ${ }^{9,27,28,30,37,40,48,53,54}$ It was also possible for studies to report more than occupation (Table DS2). For example, Agerbo et $a l^{27}$ reported suicide mortality for 53 different occupational groups, whereas Browning et al, ${ }^{8}$ reported suicide among farmers in three different North American states. Jansson et $a l^{34}$ provided suicide mortality for one occupational group (chimney sweeps).

Various effect measures were used. As detailed in Table DS2, 16 studies used rate ratios (RRs), $8,9,11,27-30,32,36,38,42,43,45,48,51,56$ 11 used SMRs, ${ }^{31,33-35,37,39,41,47,49,50,52} 3$ used PMR measures ${ }^{9,40,44}$ and 4 studies used ORs. ${ }^{46,53-55}$ As suicide is a rare event in a population, these measures of risk can be seen as comparable for the purpose of meta-analysis. ${ }^{58}$ There were also a number of different referent populations used in studies on occupational suicide. One group of studies used an occupation at lower risk of suicide as a referent. ${ }^{28,42,44,46,48,55}$ A second group compared suicide in one occupational group to all other occupation groups except that of interest. ${ }^{9,11,29,53,54}$ The last group included studies that used the general working-age population as a referent. $^{8-11,29-45,47,49-52,56}$

\section{Results by ISCO categories}

Individual results conducted for each of the nine ISCO categories can been seen in online Tables DS3-12, and Fig. 2 indicates the pooled results. The pooled RRs were interpreted as the risk of suicide in the category of interest compared with the workingage population (further subgroup analyses were conducted to assess the influence of different referent populations). The highest risk of suicide was apparent in the ISCO major category 9, which was comprised of 'elementary' occupations such as labourers and cleaners $(\mathrm{RR}=1.84,95 \% \mathrm{CI} 1.46-2.33)$ and the major category 8 group, which represented plant and machine operators and ship's deck crew $(\mathrm{RR}=1.78,95 \%$ CI 1.22-2.60). There was also a particularly elevated risk among the ISCO major category 5 $(\mathrm{RR}=1.52,95 \%$ CI 1.28-1.80), which represented services such as police, and ISCO major category $6(\mathrm{RR}=1.64,95 \%$ CI $1.19-2.28)$ skilled agricultural, forestry and fishery workers. The lowest risk of suicide was seen in the highest skill-level group of managers (ISCO category $1, \mathrm{RR}=0.68,95 \%$ CI $0.50-0.93$ ) and clerical support workers (ISCO category $4, \mathrm{RR}=0.77,95 \%$ CI $0.64-0.92$ ). There was notable heterogeneity in sample size of each of the ISCO categories, reflecting differential research attention to certain occupations and skill levels. There were also notable differences in the number of studies included in each subgroup analysis, with ISCO 1 having only 8 studies (7 degrees of freedom), whereas ISCO 9 consisted of 25 studies ( 24 degrees of freedom).

\section{Results collapsed into four skill levels}

There was no evidence of elevated suicide among skill levels 3 and 4 compared with the general working-age population. There did, however, appear to be a decreasing gradient from the lowest skilled occupations (skill level 1) to the second most skilled occupation (skill level 3) (Fig. 3). The lowest ( $R R=1.76,95 \%$ CI 1.42-2.17) and second lowest skilled occupations ( $\mathrm{RR}=1.32$, 95\% CI 1.19-1.47) had a higher risk of suicide than either the highest $(\mathrm{RR}=1.16,95 \% \mathrm{CI} 0.97-1.40)$ or second highest skilled occupations $(\mathrm{RR}=0.93,95 \%$ CI $0.71-1.21)$.

\section{Sensitivity analyses and meta-regression}

A sensitivity analysis was conducted to assess the effects of gender on occupational risk of suicide, although statistical power was limited by the reduced sample sizes (Table 1). Among males, only one of the four skill-level groups (level 2) was significantly

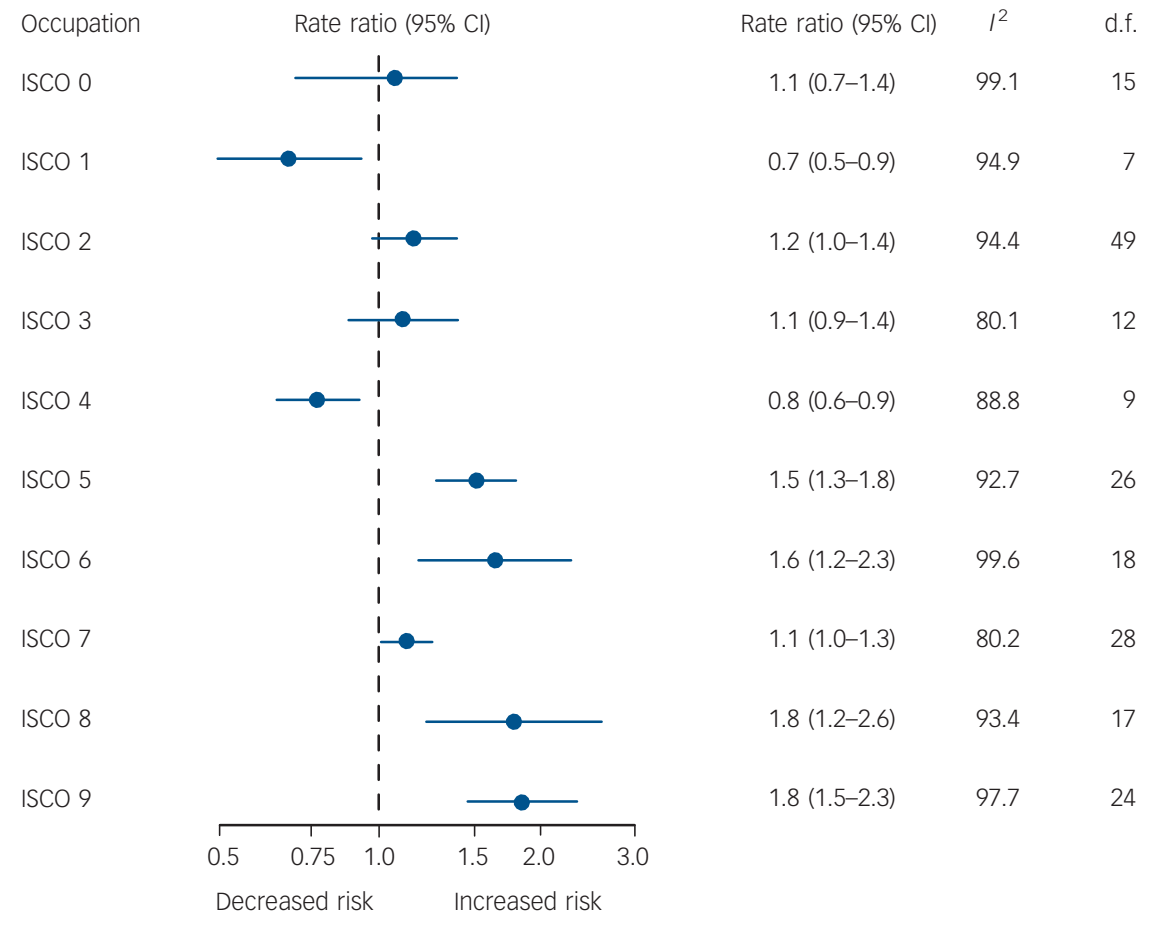

Fig. 2 Results of meta-analysis of suicide by occupation with studies classified according to International Standard Classification of Occupations (ISCO) 2008 major categories, Forrest plot. 


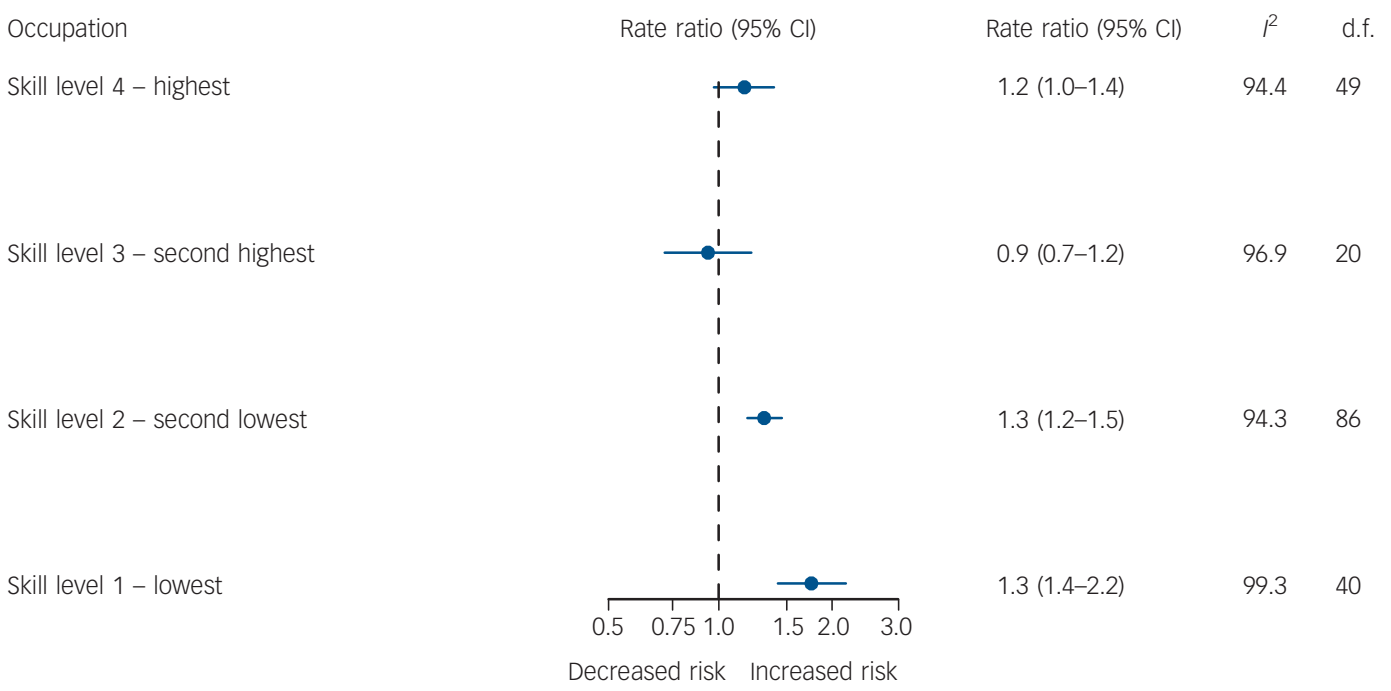

Fig. 3 Results of meta-analysis of suicide by occupation with studies classified according to International Standard Classification of Occupations (ISCO) 2008 aggregate skill level, Forrest plot.

different from an RR of 1.0. Risk was the highest in skill level 1 (i.e. the lowest skilled occupations) and decreased steadily to the highest skilled groups. For females, conversely, the highest skilllevel group showed the highest RR; there was also, however, the suggestion of a gradient for occupations classified into levels 1 to 3 (with the greatest risk being in those occupations at the lowest skill level). The analysis for females was limited by a smaller number of studies reporting female suicide.

Those studies that compared the risk of suicide with the lowest-risk occupation generally showed stronger differences than those that used the employed population overall, or all other occupations (Table 1). These studies are better able to assess an occupational skill-level gradient in suicide, as they compare results to a distinct and often minimal risk occupational group.

A final sensitivity analysis was also conducted to assess whether the relationship between occupational skill level and risk of suicide was confounded by SES (Table 2). Contrary to expectation, effect size estimates for each skill level were elevated for studies with $v$. without SES adjustment (Table 2). This is likely connected to the methodological characteristics of the studies that adjusted for SES, which tended to be measured in relation to another occupational group at lower risk of suicide rather than the general population. Therefore, the increased risk may reflect the underlying characteristics of the reference population rather than the genuine influence of SES. In any case, limitations notwithstanding, there was no evidence of confounding by SES.

\section{Heterogeneity}

Results of the meta-regression analysis showed that the use of different referent groups explained about $16.7 \%$ of the betweenstudies variance. The use of a lower risk occupation as a referent group had a significantly greater effect on RR than the use of the whole working-age population as a referent. Socioeconomic status explained about $12.2 \%$ of the between-studies variance, and those studies that controlled for SES had a significantly greater risk of suicide by occupational skill-level group than those that did not. There were no significant effects found for gender on results. After controlling for gender and SES, results suggested that the effects of different referent groups remained a significant predictor of results. There were also differences in results based on study design, with case-control studies being significantly more likely to find greater effect sizes than either occupational cohorts or general cohort studies. However, there was no statistical difference related to the type of estimate used in the meta-analysis (possibly related to the fact that all effect estimates were transformed to be made comparable before analysis was conducted) or the location of the study. However, the year during which the study took place was found to significantly influence results, and accounted for $3.8 \%$ of between-study variance.

A funnel plot (online Fig. DS1) indicated that the majority of studies had small standard errors and RR estimates spanning from under one to approximately three. Observations with RR above three had larger standard error estimates, which may reflect small sample size or other limitations. The funnel plot also indicated possible publication bias as most studies report positive effects (i.e. occupations with greater risk of suicide than working populations) rather than negative effects. There was a smaller number of outlier studies with RRs above five and with standard errors above 0.5 to 0.4 . Further investigation of possible bias using the modified Egger's test ${ }^{25}$ indicated that small study effects were evident in the results coded under ISCO major categories 1, 2, 4 and 5 (higher skill) but were not observable in those classified under ISCO major categories 3, 6, 7, 8 or 9 (lower skill).

\section{Discussion}

\section{Main findings}

This study confirms that certain occupational groups are at elevated risk of suicide compared with the general employed population, or compared with other occupational groups. At greatest risk were labourers, cleaners and elementary occupations (ISCO major category 9), followed by machine operators and ship's deck crew (ISCO major group 8). It is notable that there have been relatively few articles published on suicide in these groups, despite people employed in these jobs having a markedly higher burden of suicide than those in many other occupational categories. Significantly elevated risk was also apparent in farmers and agricultural workers (ISCO major group 6), service workers such as police (ISCO major group 5) and people in skilled trades (builders and electricians) (ISCO major group 7) compared with working-age populations. The lowest rates were seen in managers (ISCO major group 1) and clerical workers (ISCO major group 4). 


\begin{tabular}{|c|c|c|c|c|}
\hline & Rate ratio $(95 \% \mathrm{Cl})$ & $I^{2}, \%$ & $\tau^{2}$ & d.f. \\
\hline \multicolumn{5}{|l|}{ Gender } \\
\hline \multicolumn{5}{|l|}{ Males } \\
\hline Skill level 1 & $1.30(0.94-1.80)$ & 99.7 & 0.3732 & 13 \\
\hline Skill level 2 & $1.19(1.02-1.39)$ & 95.4 & 0.1219 & 22 \\
\hline Skill level 3 & $0.89(0.48-1.64)$ & 98.3 & 0.4642 & 4 \\
\hline Skill level 4 & $0.94(0.70-1.27)$ & 96.7 & 0.3834 & 18 \\
\hline \multicolumn{5}{|l|}{ Females } \\
\hline Skill level 1 & $1.14(0.82-1.60)$ & 92.8 & 0.1929 & 8 \\
\hline Skill level 2 & $1.16(0.92-1.46)$ & 91.1 & 0.1652 & 20 \\
\hline Skill level 3 & $0.64(0.37-1.10)$ & 95.2 & 0.2458 & 3 \\
\hline Skill level 4 & $1.28(0.95-1.71)$ & 88.7 & 0.306 & 18 \\
\hline \multicolumn{5}{|c|}{ Referent group } \\
\hline \multicolumn{5}{|c|}{ Working-age population } \\
\hline Skill level 1 & $1.02(0.71-1.48)$ & 99.7 & 0.4150 & 11 \\
\hline Skill level 2 & $1.06(0.90-1.25)$ & 96.2 & 0.1654 & 29 \\
\hline Skill level 3 & $0.72(0.44-1.18)$ & 98.9 & 0.3091 & 4 \\
\hline Skill level 4 & $1.01(0.77-1.33)$ & 96.2 & 0.4253 & 25 \\
\hline \multicolumn{5}{|c|}{ One other (lower risk) occupational group } \\
\hline Skill level 1 & $2.78(1.85-4.18)$ & 97.2 & 0.8212 & 20 \\
\hline Skill level 2 & $1.53(1.34-1.75)$ & 81.9 & 0.1667 & 51 \\
\hline Skill level 3 & $1.07(0.88-1.29)$ & 54.5 & 0.0688 & 13 \\
\hline Skill level 4 & $1.34(1.11-1.63)$ & 70.8 & 0.1221 & 19 \\
\hline \multicolumn{5}{|c|}{ All other occupational groups } \\
\hline Skill level 1 & $1.39(1.54-1.68)$ & 94.8 & 0.0091 & 7 \\
\hline Skill level 2 & $1.00(0.89-1.13)$ & 44.9 & 0.0071 & 4 \\
\hline Skill level $3^{a}$ & $0.65(0.56-0.75)$ & 0.0 & 0.000 & 1 \\
\hline Skill level 4 & $1.32(0.72-2.44)$ & 94.9 & 0.3455 & 3 \\
\hline
\end{tabular}

Results of this meta-analysis also indicated significant differences by skill level, with the lowest and the second lowest skilled professions being at particularly elevated risk. The second most skilled occupations had the lowest rates of suicide, but this was not significantly different from the working-age population.

\section{Possible explanations for our findings}

The greater risk of suicide in lower skilled occupational groups may be symptomatic of wider social and economic disadvantages, including lower education, income and access to health services. ${ }^{59}$ This explanation has been noted in a recent paper by Roberts et $a l^{60}$ (unfortunately published after our analyses were completed and so it was not included in the meta-analysis), which also found that lower skilled occupations were at greatest risk of suicide in the UK, and that variation in suicide rates that was explained by occupational skill level increased significantly between 1979 and 2005. However, variation in SES disadvantage cannot explain the elevated suicide rates among those employed in highly skilled occupations, as these people are likely to be well paid and highly educated (as suggested in past research). ${ }^{61}$ In saying this, a limitation of this study is that it was unable to adequately assess the role of socioeconomic factors due to differences in the underlying methodological design of studies that did and did not control for SES. Most studies that did control for SES used another occupational group as a reference category (which led to greater differences in RR estimates), whereas most of those that did not control for SES used the entire working population as reference (which led to smaller differences).

Access to lethal suicide methods through work may also explain some of the observed results, particularly the higher risk of suicide in ISCO categories containing farmers, police, military and medical professionals than other occupations. ${ }^{18,19,62}$ An investigation of the methods used in suicide by occupational groups conducted in New Zealand ${ }^{52}$ found that farmers were more likely to use firearms as a method to take their own life, whereas health professionals were more likely to overdose on drugs. However, those who died by suicide in the military did

\begin{tabular}{|c|c|c|c|c|}
\hline Socioeconomic status (SES) adjustment & Rate ratio $(95 \% \mathrm{Cl})$ & $I^{2}, \%$ & $\tau^{2}$ & d.f. \\
\hline \multicolumn{5}{|l|}{ Adjusted for SES } \\
\hline Skill level 1 & $2.28(1.68-3.10)$ & 97.2 & 0.3851 & 18 \\
\hline Skill level 2 & $1.51(1.35-1.69)$ & 33.3 & 0.0155 & 19 \\
\hline Skill level 3 & $1.92(0.88-4.17)$ & 64.8 & 0.3000 & 2 \\
\hline Skill level 4 & $1.53(1.28-1.83)$ & 49.6 & 0.0454 & 13 \\
\hline \multicolumn{5}{|l|}{ Not adjusted for SES } \\
\hline Skill level 1 & $1.44(1.09-1.90)$ & 99.5 & 0.4206 & 21 \\
\hline Skill level 2 & $1.25(1.11-1.41)$ & 95.4 & 0.3751 & 66 \\
\hline Skill level 3 & $0.85(0.65-1.12)$ & 97.1 & 0.3056 & 17 \\
\hline Skill level 4 & $1.04(0.84-1.29)$ & 95.4 & 0.3751 & 35 \\
\hline
\end{tabular}


not use firearms in this study, despite these being readily available. This suggests that access to and familiarity with lethal suicide methods underpin some, but certainly not all, occupational suicides.

Alternatively, variations in suicide may reflect occupationspecific factors. There has been some research suggesting that the higher burden of suicide in agriculturally based occupations is connected to exposure to pesticides (aside from the intentional use of pesticides as a means of suicide). ${ }^{8,49,63}$ A cohort study by Berlin et $a l^{64}$ found that people in occupations regularly exposed to solvents and toxins (for example house painters, mechanics, workers in the chemical-processing industry and printers) had between 1.5 and 2 times the risk of suicide compared with the general population. Explanations for these findings stem from research showing that workers exposed to certain pesticides have long-term neurological changes that may contribute to depressive symptoms. ${ }^{65,66}$ The idea that pesticides increase the risk of suicide in certain occupations has been called into question in recent studies. ${ }^{67,68}$ One possible explanation for these differences between studies is that there may have been declining exposure to chemicals over time. It is also possible that exposure is stronger in some areas than others, which would suggest that the geographical characteristics of studies is also important.

The quality of psychosocial working conditions may also explain variation in suicide by occupation. Although there have been only a few studies on the topic, those suggest an association between psychosocial job stressors (for example low job control, low social support, and high job demands) and suicide. ${ }^{13-17} \mathrm{~A}$ study by Ostry et $a l^{17}$ found that psychological demands and social support at work were associated with both completed and attempted suicide in a cohort of sawmill workers. A cohort study with 9-year follow-up in Japan found a fourfold increase in the risk of suicide among men with low control at work. ${ }^{69}$ Psychosocial job stressors have also been found to be associated with intermediaries of suicide such as depression, ${ }^{70,71}$ and pattern by occupational skill level. ${ }^{20}$ Considering this, it is plausible that psychosocial job stressors have an influence on suicide mortality. Finally, it is impossible to rule out the possibility that certain occupations are at risk because of the underlying characteristics of the individuals employed in them. ${ }^{5}$

\section{Strengths and limitations}

The main strengths of this paper lie in its classification of occupations using a standardised coding framework. Not only does this allow researchers the ability to compare like-occupations across studies, it also enables the investigation of higher-order patterning of occupation and suicide across the entire working population. At the same time, there were several methodological weaknesses. In some cases, available information on occupation was insufficient for unambiguous skill-group level classification. For example, those employed in the agricultural industry could be defined as either 'skilled agricultural forestry and fishery workers' (ISCO major category 6) or under 'elementary occupations' (ISCO major category 9). Unless specified by the article, occupations were classified under the first of these categories, which would tend to reduce occupational skill-level differences, biasing towards the null. Similarly, those employed in the construction and building industry could be classified in either ISCO major category 7 'craft and related trade workers' or under ISCO 9 major category 'labourers in mining, construction, manufacturing and transport'. In this case, classification of occupation was dependent on the amount of detail provided in the source article. With respect to the assessment of occupational skill-level differences, these problems were offset by collapsing of occupational skill level from nine to four groups. Limitations in the search strategy also may have meant that eligible studies may have been excluded or screened out of the meta-analytical review.

Another methodological weakness is that many studies on occupational suicide use effect measures such as SMRs and PMRs, which may obscure important effect modifiers such as SES. The differences in referent groups between studies is also a problem and there is noticeable variation between studies that used the general working population or another occupational group as a reference category (as seen in sensitivity analysis in Table 1). ${ }^{72}$ There may also be multiple comparisons between a control group and several occupational groups within a single study. We did not adjust for this as the only information available were log-transformed effect sizes for categorical outcomes (OR, RR, etc.) and their accompanying log standard errors/confidence intervals. If these multiple comparisons did influence the metaanalysis, we would expect results to be closer to null and produce more conservative findings. The different methodological characteristics between those studies that did and did not control for SES meant that we were unable to adequately assess the role of wider social and economic inequalities on the relationship between occupation and suicide.

There was also a large amount of heterogeneity between studies, which is likely because of inherent differences in how occupation was defined and classified, as well as connected to variation in when the study was conducted, and the social and geographical context of the study. At the same time, there were clear similarities between studies grouped with the major categories of ISCO 2008. This reflects the ongoing tension about whether the primary objectives of meta-analytical studies should be the estimation of an overall summary or average effect across studies, or the identification and estimation of differences between studies. $^{58}$

\section{Implications}

Although the meta-analyses was subject to a high degree of heterogeneity as a result of variation in study designs, referent populations and location of study, results indicate patterning in suicide mortality by occupational skill-level group. Future research is needed in order to validate these findings, and to investigate the high level of heterogeneity between studies. From a public health perspective, the results of this meta-analysis could suggest a need to prioritise intervention and prevention efforts for people employed in lower skilled jobs, particularly as these individuals may have limited access to the economic, social and health resources (as likely buffering or protective influences) available to those in higher skilled occupations. A particularly important (and understudied) area of work is the relationship between exposure to psychosocial job stressors and suicide. It would also be beneficial to understand the factors that protect some occupational groups from suicide compared with the general working population. Considering the workplace is increasingly recognised as a venue to screen and effectively manage mental health, ${ }^{73,74}$ further research and investment into workplace suicide prevention efforts are necessary. Following best practice in workplace mental health promotion, ${ }^{75}$ these interventions should aim to address job stressors and other work-related influences, while also building on factors that are protective against suicide by promoting positive mental health and help-seeking.

\section{Funding}

The National Health and Medical Research Council Capacity Building Grant in Population Health and Health Services Research (ID: 546248) provided salary support for A.D.M. 
Allison Milner, BpsychSc (Hons), PhD, The McCaughey VicHealth Centre for Community Wellbeing, Melbourne School of Population and Global Health, The University of Melbourne, Melbourne; Matthew J. Spittal, PhD, Mbio, Jane Pirkis BA(Hons), MPsych, MAppEpid, PhD, Centre for Health Policy, Programs and Economics, Melbourne School of Population and Global Health, The University of Melbourne, Melbourne; Anthony D. LaMontagne, SCD, MA, MEd, The McCaughey VicHealth Centre for Community Wellbeing, Melbourne School of Population and Global Health, The University of Melbourne, Melbourne, Australia

Correspondence: Allison Milner, The McCaughey VicHealth Centre for Community Wellbeing, Melbourne School of Population and Global Health, The University of Melbourne, Level 5, 207 Bouverie Street, Melbourne, VIC 3010, Australia.Email: allison.milner@unimelb.edu.au

First received 24 Feb 2013, final revision 25 Apr 2013, accepted 1 May 2013

\section{References}

1 Reinhart GR, Linden LL. Suicide by industry and occupation: a structuralchange approach. Suicide Life Threat Behav 1982; 12: 34-45.

2 Tuckman J, Youngman WF, Kreizman G. Occupation and suicide. Ind Med Surg 1964; 33: 818-20.

3 Stark C, Belbin A, Hopkins P, Gibbs D, Hay A, Gunnell D. Male suicide and occupation in Scotland. Health stat $Q$ 2006; Spring: 26-9.

4 Platt B, Hawton K, Simkin S, Mellanby RJ. Systematic review of the prevalence of suicide in veterinary surgeons. Occup Med 2010; 60: 436-46.

5 Bartram DJ, Baldwin DS. Veterinary surgeons and suicide: influences, opportunities and research directions. Vet Rec 2008; 162: 36-40.

6 Judd F, Jackson H, Fraser C, Murray G, Robins G, Komiti A. Understanding suicide in Australian farmers. Soc Psychiatry Psychiatr Epidemiol 2006; 41 $1-10$.

7 Dongre AR, Deshmukh PR. Farmers' suicides in the Vidarbha region of Maharashtra, India: a qualitative exploration of their causes. J Inj Violence Res 2012; 4: 2-6.

8 Browning SR, Westneat SC, McKnight RH. Suicides among farmers in three southeastern states, 1990-1998. J Agric Saf Health 2008; 14: 461-72.

9 Violanti JM, Vena JE, Marshall JR, Petralia S. A comparative evaluation of police suicide rate validity. Suicide Life Threat Behav 1996; 26: 79-85.

10 Violanti JM. Suicide or undetermined? A national assessment of police suicide death classification. Int J Emerg Ment Health 2010; 12: 89-94.

11 Vena JE, Violanti JM, Marshall J, Fiedler RC. Mortality of a municipal worker cohort: 111. Police officers. Am J Ind Med 1986; 10: 383-97.

12 Booth $\mathrm{N}$, Briscoe $\mathrm{M}$, Powell R. Suicide in the farming community: methods used and contact with health services. Occup Environ Med 2000; 57: 642-4.

13 Nishimura M, Terao T, Soeda S, Nakamura J, Iwata N, Sakamoto K. Suicide and occupation: further supportive evidence for their relevance. Prog Neuropsychopharmacol Biol Psychiatry 2004; 28: 83-7.

14 Schneider B, Grebner K, Schnabel A, Hampel H, Georgi K, Seidler A. Impact of employment status and work-related factors on risk of completed suicide. A case-control psychological autopsy study. Psychiatry Res 2011; 190: 265-70

15 Woo JM, Postolache TT. The impact of work environment on mood disorders and suicide: evidence and implications. Int J Disabil Hum Dev 2008; 7: 185-200.

16 Amagasa T, Nakayama T, Takahashi Y. Karojisatsu in Japan: characteristics of 22 cases of work-related suicide. J Occup Health 2005; 47: 157-64.

17 Ostry A, Maggi S, Tansey J, Dunn J, Hershler R, Chen L, et al. The impact of psychosocial work conditions on attempted and completed suicide among western Canadian sawmill workers. Scand J Public Health 2007; 35: 265-71.

18 Bedeian AG. Suicide and occupation: a review. J Vocat Behav 1982; 21: 206-23.

19 Boxer PA, Burnett C, Swanson N. Suicide and occupation: a review of the literature. J Occup Environ Med 1995; 37: 442-52.

20 LaMontagne AD, Keegel T, Vallance D, Ostry A, Wolfe R. Job strain attributable depression in a sample of working Australians: assessing the contribution to health inequalities. BMC Public Health 2008; 8: 181.

21 International Labour Organization. ISCO-08 structure (EXCel). ILO, 2008 (http://www.ilo.org/public/english/bureau/stat/isco/docs/struct08.xls).

22 International Labour Organization. International Standard Classification of Occupations (ISCO-08) - Conceptual Framework. ILO, 2008 (http:// www.ilo.org/public/english/bureau/stat/isco/docs/annex1.doc).

23 Harbord RM, Higgins JPT. Meta-regression in Stata. Stata J 2008; 8: 493-519.

24 Sterne JAC, Harbord RM. Funnel plots in meta-analysis. Stata J 2004; 4: $127-41$.
25 Harbord RM, Harris RJ, Sterne JAC. Updated test for small-study effects in meta-analyses. Stata J 2009; 9: 197-210.

26 Sanderson S, Tatt ID, Higgins JP. Tools for assessing quality and susceptibility to bias in observational studies in epidemiology: a systematic review and annotated bibliography. Int J Epidemiol 2007; 36: 666-76.

27 Agerbo E, Gunnell D, Bonde JP, Mortensen PB, Nordentoft M. Suicide and occupation: the impact of socio-economic, demographic and psychiatric differences. Psychol Med 2007; 37: 1131-40.

28 Kposowa AJ. Suicide mortality in the United States: differentials by industrial and occupational groups. Am J Ind Med 1999; 36: 645-52.

29 Mustard CA, Bielecky A, Etches J, Wilkins R, Tjepkema M, Amick BC, et al. Suicide mortality by occupation in Canada, 1991-2001. Can J Psychiatry 2010; 55: 369-76.

30 Notkola VJ, Martikainen P, Leino PI. Time trends in mortality in forestry and construction workers in Finland 1970-85 and impact of adjustment for socioeconomic variables. J Epidemiol Community Health 1993; 47: 186-91.

31 Baris D, Armstrong BG, Deadman J, Theriault G. A mortality study of electrical utility workers in Quebec. Occup Environ Med 1996; 53: 25-31.

32 Brandt LPA, Kirk NU, Jensen OC, Hansen HL. Mortality among Danish merchant seamen from 1970 to 1985. Am J Ind Med 1994; 25: 867-76.

33 Hansen $\mathrm{HL}$, Jensen J. Female seafarers adopt the high risk lifestyle of male seafarers. Occup Environ Med 1998; 55: 49-51.

34 Jansson C, Alderling M, Hogstedt C, Gustavsson P. Mortality among Swedish chimney sweeps (1952-2006): an extended cohort study. Occup Environ Med 2012; 69: 41-7.

35 Jarvholm B, Stenberg A. Suicide mortality among electricians in the Swedish construction industry. Occup Environ Med 2002; 59: 199-200.

36 Mahon MJ, Tobin JP, Cusack DA, Kelleher C, Malone KM. Suicide among regular-duty military personnel: a retrospective case-control study of occupation-specific risk factors for workplace suicide. Am J Psychiatry 2005; 162: 1688-96.

37 Olsen J, Sabroe S. Mortality among bricklayers and carpenters/cabinet makers. Scand J Soc Med 1979; 7: 49-54.

38 Ponteva M. Aspects of the suicide of conscripts in the Finnish Defence Forces. Psychiatria Fennica Suppl 1983; 2: 97-103.

39 Rafnsson V, Gunnarsdóttir H. Risk of fatal accidents occurring other than at sea among Icelandic seamen. BMJ 1993; 306: 1379-81.

40 Robinson CF, Petersen M, Palu S. Mortality patterns among electrical workers employed in the U.S. construction industry, 1982-1987. Am J Ind Med 1999; 36: 630-7.

41 Tanaka H, Nishio N, Murakami E, Mukai M, Kinoshita N, Mor I. Mortality and causes of death among Japanese school personnel between 1992 and 1996. J Occup Health 2001; 43: 129-35.

42 Andersen K, Hawgood J, Klieve H, Kolves K, De Leo D. Suicide in selected occupations in Queensland: evidence from the state suicide register. Aust N Z J Psychiatry 2010; 44: 243-9.

43 Fear NT, Williamson S. Suicide and Open Verdict Deaths among Males in the UK Regular Armed Forces: Comparison with the UK Civilian Population and the US Military. Defence Analytic Services, 2003 (http:// www.barronpsych.com.au/research/UKArmysuicide2003.pdf).

44 Frank $\mathrm{E}$, Biola $\mathrm{H}$, Burnett CA. Mortality rates and causes among U.S. physicians. Am J Prev Med 2000; 19: 155-9.

45 Hytten K, Weisaeth L. Suicide among soldiers and young men in the Nordic countries 1977-1984. Acta Psychiatr Scand 1989; 79: 224-8.

46 Kim MD, Hong SC, Lee SY, Kwak YS, Lee Cl, Hwang SW, et al. Suicide risk in relation to social class: a national register-based study of adult suicides in Korea, 1999-2001. Int J Soc Psych 2006; 52: 138-51.

47 King AS, Threlfall WJ, Band PR, Gallagher RP. Mortality among female registered nurses and school teachers in British Columbia. Am J Ind Med 1994; 26: 125-32.

48 Liu T, Waterbor JW. Comparison of suicide rates among industrial groups. Am J Ind Med 1994; 25: 197-203.

49 Meltzer H, Griffiths C, Brock A, Rooney C, Jenkins R. Patterns of suicide by occupation in England and Wales: 2001-2005. Br J Psychiatry 2008; 193 73-6.

50 Miller JM, Beaumont JJ. Suicide, cancer, and other causes of death among California veterinarians, 1960-1992. Am J Ind Med 1995; 27: 37-49.

51 Sentell JW, Lacroix M, Sentell JV, Finsuen K. Predictive patterns of suicidal behaviour: the United States armed services versus the civilian population Mil Med 1997; 162: 168-71.

52 Skegg K, Firth H, Gray A, Cox B. Suicide by occupation: does access to means increase the risk? Aust N Z J Psychiatry 2010; 44: 429-34.

53 Stack S. Gender and suicide risk among artists: a multivariate analysis. Suicide Life Threat Behav 1996; 26: 374-9. 
54 Stack S. Suicide among carpenters: a multivariate analysis. Omega 1999; 39 229-32.

55 van Wijngaarden E. An exploratory investigation of suicide and occupational exposure. J Occup Environ Med 2003; 45: 96-101.

56 Wong A, Escobar M, Lesage A, Loyer M, Vanier C, Sakinofsky I. Are UN peacekeepers at risk for suicide? Suicide Life Threat Behav 2001; 31: 103-12.

57 van Wijngaarden E, Savitz DA, Kleckner RC, Cai J, Loomis D. Exposure to electromagnetic fields and suicide among electric utility workers: a nested case-control study. West J Med 2000; 173: 94-100.

58 Greenland S. Meta-analysis. In Modern Epidemiology (eds KJ Rothman, S Greenland): 643-73. Lippincott-Raven, 1998.

59 Taylor R, Page A, Morrell S, Carter G, Harrison J. Socio-economic differentials in mental disorders and suicide attempts in Australia. Br J Psychiatry 2004; 185: 486-93.

60 Roberts SE, Jaremin B, Lloyd K. High-risk occupations for suicide. Psychol Med 2013; 43: 1231-40.

61 Agerbo E, Mortensen PB, Qin P, Westergaard-Nielsen N. Risk of suicide in relation to income level in people admitted to hospital with mental illness: nested case-control study. BMJ 2001; 332: 334-5.

62 Stack S. Occupation and suicide. Soc Sci Q 2001; 82: 384-96.

63 Lee E, Burnett CA, Lalich N, Cameron LL, Sestito JP. Proportionate mortality of crop and livestock farmers in the United States, 1984-1993. Am J Ind Med 2002; 42: 410-20.

64 Berlin K, Edling C, Persson B, Ahlborg G, Hillert L, Hogstedt B, et al. Cancer incidence and mortality of patients with suspected solvent-related disorders. Scand J Work Environ Health 1995; 21: 362-7.

65 Steenland K, Jenkins B, Ames RG, O'Malley M, Chrislip D, Russo J. Chronic neurological sequelae to organophosphate pesticide poisoning. Am J Public Health 1994; 84: 731-6.
66 Stallones L, Beseler C. Pesticide poisoning and depressive symptoms among farm residents. Ann Epidemiol 2002; 12: 389-94.

67 MacFarlane E, Simpson P, Benke G, Sim MR. Suicide in Australian pesticideexposed workers. Occup Med 2011; 61: 259-64.

68 Beard JD, Umbach DM, Hoppin JA, Richards M, Alavanja MCR, Blair A, et al. suicide and pesticide use among pesticide applicators and their spouses in the agricultural health study. Environ Health Perspect 2011; 119.

69 Tsutsumi A, Kayaba K, Ojima T, Ishikawa S, Kawakami N. Low control at work and the risk of suicide in Japanese men: a prospective cohort study. Psychother Psychosom 2007; 76: 177-85.

70 LaMontagne AD, Keegel T, Louie AM, Ostry A. Job stress as a preventable upstream determinant of common mental disorders: a review for practitioners and policy-makers. Advances Ment Health 2010; 9: 17-35.

71 Stansfeld S, Candy B. Psychosocial work environment and mental health a meta-analytic review. Scand J Work Environ Health 2006; 32: 443-62.

72 Brugha TS, Matthews R, Morgan Z, Hill T, Alonso J, Jones DR. Methodology and reporting of systematic reviews and meta-analyses of observational studies in psychiatric epidemiology: systematic review. Br J Psychiatry 2012; 200: 446-53.

73 Barry MM, Jenkins R. Promotion mental health in the workplace. In Implementing Mental Health Promotion (eds MM Barry, R Jenkins): 215-53. Churchill Livingston, 2007.

74 LaMontagne AD, D'Souza RM, Shann CB. Socio-demographic and work setting correlates of poor mental health in a population sample of working Victorians: application in evidence-based intervention priority setting. Int J Ment Health Promot 2012; 14: 109-22.

75 LaMontagne AD, Keegel T, Vallance DA. Protecting and promoting mental health in the workplace: developing a systems approach to job stress. Health Promot J Austr 2007; 18: 221-8.

\section{Obsessive-compulsive disorder}

Lynne Drummond

Obsessive-compulsive disorder is common, affecting up to $3 \%$ of adults and children. Obsessions are anxiogenic intrusive thoughts images or impulses. Compulsions are anxiolytic thoughts or behaviours which reduce the anxiety induced by obsessions. The relief of anxiety reduction maintains the obsessive-compulsive cycle. Symptoms range from mild to life-threatening, where lack of personal care can have potentially lethal consequences. A high proportion demonstrate suicidal behaviours. Most patients, irrespective of symptom severity, respond to treatment with graded exposure or with serotonin reuptake inhibitors, but some continue with a chronic or chronic relapsing course requiring ongoing psychiatric input and specialist interventions. 